\title{
Treatment of complete esophageal stenosis using endoscopic ultrasound-guided puncture: a novel technique for access to the distal lumen
}

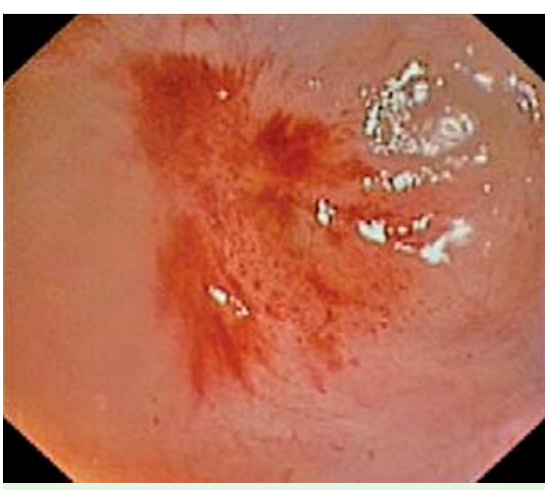

Fig. 1 Endoscopic view, showing complete obliteration of the esophageal lumen after highdose chemoradiation in a 62-year-old woman.

Treatment of locally advanced esophageal cancers with high-dose definitive concomitant chemoradiotherapy can lead to high-grade esophageal strictures, or, rarely, total obliteration of the lumen. Strictures can be successfully treated with various endoscopic techniques; however, complete obstruction is a technically challenging problem. Anterograde endoscopic techniques carry the risk of perforation or bleeding. A combined anterograde-retrograde dilation technique, described in a few reports, is another option but requires retrograde access through a prior ostomy [1-4].

We report a novel method for managing complete esophageal obstruction using endoscopic ultrasound (EUS)-guided puncture for access to the distal lumen, previously described only in a case of total colonic stricture using a prototype forward-view echoendoscope [5].

A 62-year-old woman had received highdose chemoradiation for a squamous cell esophageal carcinoma (stage IIIC) and her esophagus had completely occluded, with severe compromise to her quality of life ( $\bullet$ Fig. 1). Several attempts to pass a guide wire though the stricture were unsuccessful.

We decided to attempt recanalization of the lumen using an EUS-guided access. The linear echoendoscope (GF-UCT140-

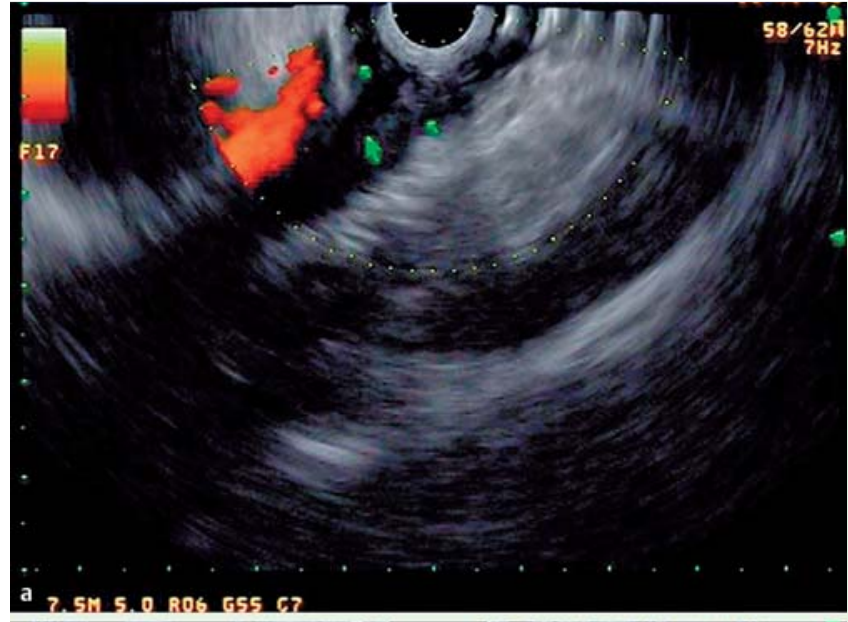

Fig. 2 a, b EUS

images of the esophageal total stricture. a A thickened esophageal wall (arrows) continues through the stenosis. b EUS image of the 19G needle through the stricture (arrow).

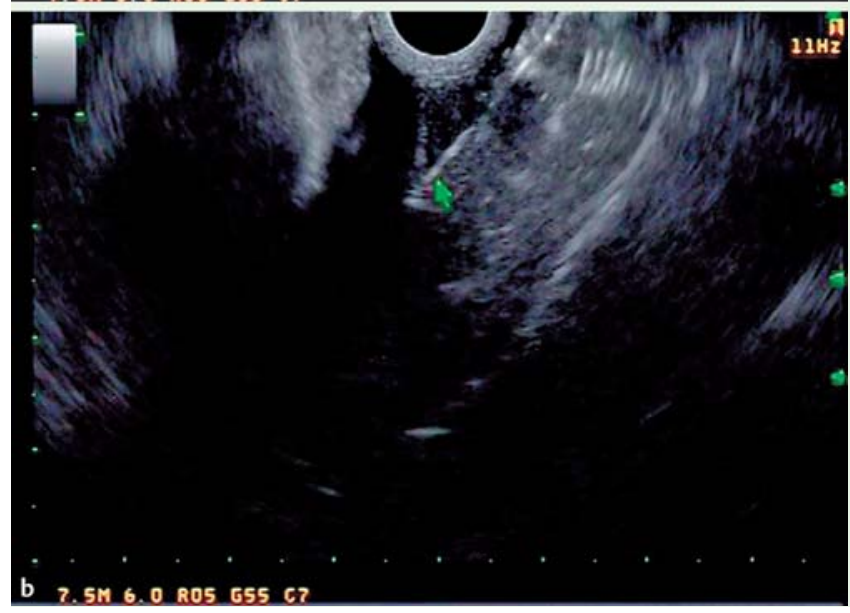

AL5; Olympus, Tokyo, Japan) was advanced $24 \mathrm{~cm}$ from the incisors and the distal esophageal lumen was identified from the proximal end on the EUS image ( $\bullet$ Fig. 2 a). A 19G needle (Expect Flex; Boston Scientific Corp, Natick, Massachusetts, USA) was used to puncture the obstructed lumen under EUS guidance ( $\bullet$ Fig. 2 b). Contrast filling was visualized under fluoroscopy and a 0.035-inch guide wire (Microvasive Jagwire; Boston Scientific) was advanced through the EUS needle ( Fig.3a,b). An 8-mm biliary balloon (Hurricane RX; Boston Scientific) was used to perform a first dilation under endoscopic and fluoroscopic guidance $(\bullet$ Fig.3c). The endoscopic appearance after dilation was satisfactory, with reestablishment of luminal continuity (๑ Video 1).

The patient underwent four additional endoscopic balloon dilations of up to $15 \mathrm{~mm}$ ( $\bullet$ Fig.4). She responded well, gaining the ability to swallow secretions, drinks, and soft food, and without evidence of delayed complications.

\section{Video 1}

Successful treatment of a completely obstructed esophageal stricture using endoscopic ultrasound-guided puncture. 

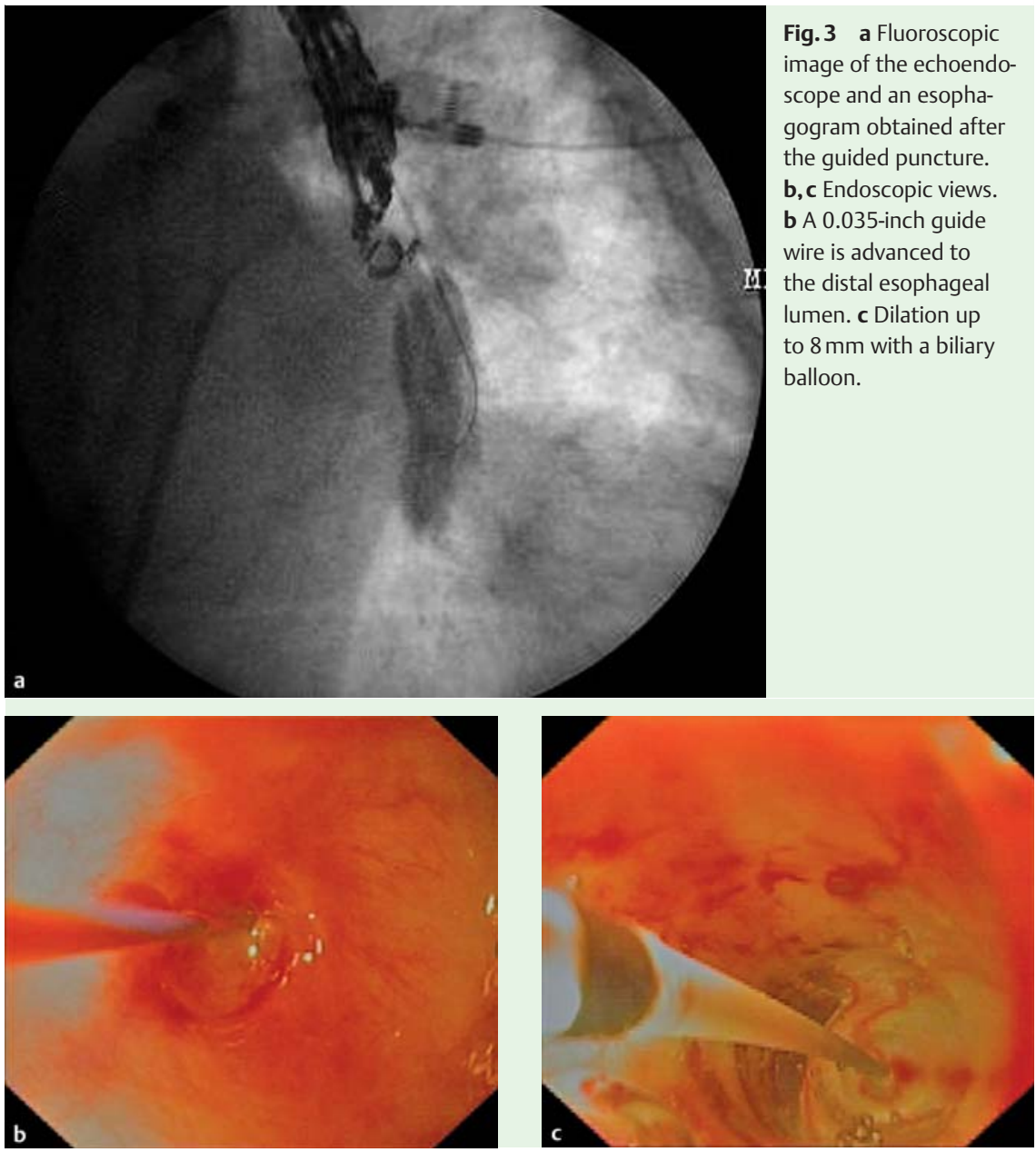

Endoscopy_UCTN_Code_CCL_1AB_2AC_3AD

\section{Competing interests: None}

Joan B. Gornals ${ }^{1}$, Claudia Consiglieri ${ }^{1}$, Josep M. Castellvi ${ }^{1}$, Xavier Ariza ${ }^{1}$, Mariona Calvo ${ }^{2}$, Maica Galan ${ }^{2}$

${ }^{1}$ Endoscopy Unit, Department of Digestive Diseases, Hospital Universitari de Bellvitge-IDIBELL, Barcelona, Spain

${ }^{2}$ Department of Medical Oncology, Institut d'Oncologia DiR-IDIBELL, Barcelona, Spain
Fig. 3 a Fluoroscopic image of the echoendoscope and an esophagogram obtained after the guided puncture. b, c Endoscopic views. b A 0.035-inch guide wire is advanced to the distal esophageal lumen. c Dilation up to $8 \mathrm{~mm}$ with a biliary balloon.

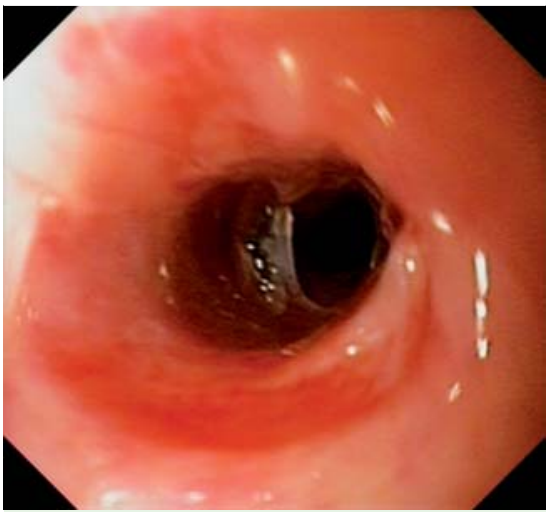

Fig. 4 Endoscopic view after two balloon dilation sessions up to $15 \mathrm{~mm}$, at 8-weeks followup after recanalization.

4 Bueno R, Swanson SJ, Jaklitsch MT et al. Combined antegrade and retrograde dilation: a new endoscopic technique in the management of complex esophageal obstruction. Gastrointest Endosc 2001; 54: 368 - 372

5 De Lusong MA, Shah JN, Soektino $R$ et al. Treatment of a completely obstructed colonic anastomotic stricture by using a prototype forward-array echoendoscope and facilitated by SpyGlass (with videos). Gastrointest Endosc 2008; 68: 988-992

\section{Bibliography}

DOI http://dx.doi.org/

10.1055/s-0033-1358932

Endoscopy 2014; 46: E2-E3

(c) Georg Thieme Verlag KG

Stuttgart · New York

ISSN 0013-726X

1 Goguen LA, Norris CM, Jaklitsch MT et al. Combined antegrade and retrograde esophageal dilation for head and neck cancerrelated complete esophageal stenosis. Laryngoscope 2010; 120: 261 - 266

2 Mukherjee K, Cash MP, Burkey BB et al. Antegrade and retrograde endoscopy for treatment of esophageal stricture. Am Surg 2008; 74: 686-687

3 Gornals JB, Nogueira J, Castellvi JM et al. Combined antegrade and retrograde esophageal endoscopic dilation for radiation-induced complete esophageal stenosis. Dig Endosc 2012; 24: 483 